\title{
Do changes in pulse pressure variation and inferior vena cava distensibility during passive leg raising and tidal volume challenge detect preload responsiveness in case of low tidal volume ventilation?
}

\author{
Temistocle Taccheri* ${ }^{*}$, Francesco Gavelli, Jean-Louis Teboul, Rui Shi and Xavier Monnet
}

\begin{abstract}
Background: In patients ventilated with tidal volume $(V t)<8 \mathrm{~mL} / \mathrm{kg}$, pulse pressure variation (PPV) and, likely, the variation of distensibility of the inferior vena cava diameter (IVCDV) are unable to detect preload responsiveness. In this condition, passive leg raising (PLR) could be used, but it requires a measurement of cardiac output. The tidal volume (Vt) challenge (PPV changes induced by a 1-min increase in Vt from 6 to $8 \mathrm{~mL} / \mathrm{kg}$ ) is another alternative, but it requires an arterial line. We tested whether, in case of $\mathrm{Vt}=6 \mathrm{~mL} / \mathrm{kg}$, the effects of PLR could be assessed through changes in PPV $\left(\triangle P P V_{P L R}\right)$ or in IVCDV $\left(\triangle I V C D V_{P L R}\right)$ rather than changes in cardiac output, and whether the effects of the Vt challenge could be assessed by changes in IVCDV $\left(\triangle I V C D V_{V t}\right)$ rather than changes in PPV $\left(\triangle P P V_{V t}\right)$.

Methods: In 30 critically ill patients without spontaneous breathing and cardiac arrhythmias, ventilated with $\mathrm{Vt}=6 \mathrm{~mL} / \mathrm{kg}$, we measured cardiac index (CI) (PiCCO2), IVCDV and PPV before/during a PLR test and before/during a $V t$ challenge. A PLR-induced increase in $\mathrm{Cl} \geq 10 \%$ defined preload responsiveness.

Results: At baseline, IVCDV was not different between preload responders $(n=15)$ and non-responders. Compared to non-responders, PPV and IVCDV decreased more during PLR (by $-38 \pm 16 \%$ and $-26 \pm 28 \%$, respectively) and increased more during the Vt challenge (by $64 \pm 42 \%$ and $91 \pm 72 \%$, respectively) in responders. $\triangle P P V_{P L R}$, expressed either as absolute or as percent relative changes, detected preload responsiveness (area under the receiver operating curve, AUROC: $0.98 \pm 0.02$ for both). $\triangle I V C D V_{P L R}$ detected preload responsiveness only when expressed in absolute changes (AUROC: $0.76 \pm 0.10$ ), not in relative changes. $\triangle P P V_{V_{t}}$ expressed as absolute or percent relative changes, detected preload responsiveness (AUROC: $0.98 \pm 0.02$ and $0.94 \pm 0.04$, respectively). This was also the case for $\triangle I V C D V_{V^{\prime}}$ but the diagnostic threshold (1 point or 4\%) was below the least significant change of IVCDV (9[3-18]\%).
\end{abstract}

Conclusions: During mechanical ventilation with $\mathrm{Vt}=6 \mathrm{~mL} / \mathrm{kg}$, the effects of PLR can be assessed by changes in PPV. If IVCDV is used, it should be expressed in percent and not absolute changes. The effects of the Vt challenge can be

\footnotetext{
*Correspondence: taccheri.temistocle@gmail.com

AP-HP, Service de médecine intensive-réanimation, Hôpital de Bicêtre, DMU CORREVE, Inserm UMR S_999, FHU SEPSIS, Groupe de Recherche Clinique CARMAS, Université Paris-Saclay, 78, Rue du Général Leclerc, 94 270 Le Kremlin-Bicêtre, France
}

(c) The Author(s) 2021. Open Access This article is licensed under a Creative Commons Attribution 4.0 International License, which permits use, sharing, adaptation, distribution and reproduction in any medium or format, as long as you give appropriate credit to the original author(s) and the source, provide a link to the Creative Commons licence, and indicate if changes were made. The images or other third party material in this article are included in the article's Creative Commons licence, unless indicated otherwise in a credit line to the material. If material is not included in the article's Creative Commons licence and your intended use is not permitted by statutory regulation or exceeds the permitted use, you will need to obtain permission directly from the copyright holder. To view a copy of this licence, visit http://creativecommons.org/licenses/by/4.0/. The Creative Commons Public Domain Dedication waiver (http://creativeco mmons.org/publicdomain/zero/1.0/) applies to the data made available in this article, unless otherwise stated in a credit line to the data. 
assessed on PPV, but not on IVCDV, since the diagnostic threshold is too small compared to the reproducibility of this variable.

Trial registration: Agence Nationale de Sécurité du Médicament et des Produits de santé: ID-RCB: 2016-A00893-48.

Keywords: Fluid responsiveness, Stroke volume variation, Acute respiratory distress syndrome, Fluid challenge

\section{Introduction}

The oldest and most investigated way to predict fluid responsiveness during acute circulatory failure consists in measuring the respiratory variation in arterial pulse pressure (pulse pressure variation, PPV) and in stroke volume (stroke volume variations, SVV) during mechanical ventilation [1-4]. Nevertheless, PPV and SVV are limited because many clinical conditions affect their reliability. In particular, if tidal volume (Vt) is $\leq 8 \mathrm{~mL} / \mathrm{kg}$, many false negatives to these indices appear because the changes in cardiac loading conditions during ventilation are too small [3-5]. The respiratory variation of the diameter of the inferior vena cava (IVCDV) is also often used. Nevertheless, for the same reason as PPV and SVV, it should suffer from some false negatives in case of low Vt, even though this has been suggested by one study only [6] (see Additional file 1: Supplementary Table 1).

To work around this PPV limitation, some authors have suggested indexing it to changes in oesophageal pressure [7], which is not frequently measured, however. Two simpler methods have been proposed. The first is the passive leg raising (PLR) test. However, this test requires a direct measurement of cardiac output [8], which is not available in a significant number of patients. However, one can intuitively hypothesize that a decrease in PPV or IVCDV itself during a PLR test could indicate the presence of a preload dependence.

Another method for testing preload dependence in the event of low Vt is to perform a "Vt challenge" [9]. It consists in temporarily increasing the Vt from 6 to $8 \mathrm{~mL} / \mathrm{kg}$ of predicted weight and observing the induced changes in PPV. A significant increase in PPV during a Vt challenge indicates the presence of a preload dependence [10] (Additional file 1: Supplementary Figure 1).

However, measuring PPV requires an arterial catheter or a non-invasive but expensive device [11]. An alternative to measure the effects of $\mathrm{Vt}$ challenge could be to measure its effects not on PPV, but on IVCV, the measurement of which only requires a transthoracic echocardiography.

Thus, the main aim of this study was to test whether the effects of a PLR test on PPV $\left(\triangle P P V_{\text {PLR }}\right)$ and IVCV $\left(\triangle \mathrm{IVCDV}_{\mathrm{PLR}}\right)$ reliably detect preload responsiveness when $\mathrm{Vt}$ is low. The secondary goals were to test whether the effects of a Vt challenge on IVCDV $\left(\Delta \operatorname{IVCDV}_{\mathrm{Vt}}\right)$ can detect preload responsiveness and to confirm that IVCDV cannot do so in the case of Vt at $6 \mathrm{~mL} / \mathrm{kg}$.

\section{Patients and methods \\ Patients}

This prospective, interventional, one-centre study was carried out in the 25-bed medical intensive care unit of a university hospital. It has been approved by our institutional review board (Comité pour la protection des personnes Ile-de-France VII). All patients or their relatives gave informed consent.

The screening criteria were age $\geq 18$ years, a transpulmonary thermodilution device in place (PiCCO2, Pulsion Medical Systems, Feldkirchen, Germany), mechanical ventilation in the volume assist control mode with a Vt of $6 \mathrm{~mL} / \mathrm{kg}$ of predicted body weight, adaption to the ventilator, and the decision taken by the clinicians in charge to perform volume expansion. This decision was made on the basis of clinical signs of inadequate tissue perfusion such as (1) systolic blood pressure $<90 \mathrm{mmHg}$ (or a decrease $>50 \mathrm{mmHg}$ in previously hypertensive patients), (2) urine output $<0.5 \mathrm{~mL} / \mathrm{kg} /$ hour for at least $2 \mathrm{~h}$, (3) tachycardia or (4) presence of skin mottling or increased capillary refill time. It also took into account the absence of excessive risk of fluid overload, as typically indicated by the level of central venous pressure, extravascular lung water and the cumulative fluid balance.

Patients were excluded if the PLR manoeuvre was contra-indicated (intracranial hypertension) or possibly unreliable (venous compression stocking, intraabdominal hypertension [12]). Other exclusion criteria were spontaneously triggered cycles on the airway pressure waveform, cardiac arrhythmias, impossibility to obtain haemodynamic stability (defined by no change in the norepinephrine dose and no change in systolic arterial pressure $<10 \%$ within 5 min before the inclusion), poor echogenicity impeding the measurement of the IVC diameter and of the velocity time integral (VTI) in the left ventricular outflow tract.

\section{Echocardiographic measurements}

IVC sonography was performed by a 4-year experienced intensivist (TT), who holds a university degree in echocardiography. With the $3.5-\mathrm{MHz}$ cardiovascular ultrasound probe of a Philips CX50 device (Philips ultrasound system, Philips Healthcare, DA Best, The Netherlands), 
the IVC was examined in the subcostal window in longitudinal section in M-mode, $2 \mathrm{~cm}$ upstream of the origin of the hepatic veins.

The distensibility index of the IVC, which reflects the increase in its diameter on insufflation, was calculated as $\mathrm{IVCDV}=($ maximum diameter on inspiration - minimum diameter on expiration)/(mean of maximum and minimum diameters).

The VTI was measured at end expiration in the left ventricular outflow tract on the apical five-chamber window. On the apical 4-chamber view, the left ventricular ejection fraction was calculated by the biplane method of disks summation (modified Simpson's rule). The average of three consecutive cardiac cycles was used for all ultrasound measurements in case of sinus rhythm, and a representative cardiac cycle was chosen in case of atrial fibrillation [13]. Endocardial contours and VTI envelope were hand drawn.

\section{Haemodynamic measurements}

All patients had a central venous catheter in the superior vena cava territory and a thermistor-tipped catheter inserted through the femoral artery. Transpulmonary thermodilution measurements were performed by injecting $15 \mathrm{~mL}$ cold normal saline $\left(<8{ }^{\circ} \mathrm{C}\right)$ through the central venous catheter. The average from three consecutive $15-\mathrm{mL}$ injections was recorded at each time point [14] and was used to obtain CI, the global end-diastolic volume (marker of cardiac preload), the extravascular lung water and the cardiac function index (estimate of the left ventricular ejection fraction). Pulse contour analysis allowed the continuous and real-time calculation of CI after an initial calibration by thermodilution [15].

The intra-abdominal pressure was estimated from the bladder pressure. The transducer was zeroed and placed at the pubic symphysis [12].

\section{Study design}

At baseline, all patients were in the $45^{\circ}$ semi-recumbent position (Additional file 1: Supplementary Figure 2). A first set of thermodilution and echocardiographic measurements was performed, including CI (measured by thermodilution), PPV, SVV and IVCDV. Then, we performed a PLR test as previously described [8]. Pulse contour analysis-derived $\mathrm{CI}, \mathrm{PPV}$, stroke volume variation (SVV) and IVCDV were recorded at the maximal effect of PLR on CI, which occurs within 1 min [8]. A third set of measurements (CI (pulse contour analysis), PPV, SVV and IVCDV) was performed once patients were returned to the semi-recumbent position and a steady state was obtained again.

A "Vt challenge" was then performed by increasing Vt from 6 to $8 \mathrm{~mL} / \mathrm{kg}$ of predicted body weight for $1 \mathrm{~min}$
[10]. A fourth set of measurements (CI (pulse contour analysis), PPV, SVV and IVCDV) was recorded once CI remained stable. Vt was then decreased back to $6 \mathrm{~mL} /$ $\mathrm{kg}$ of predicted body weight, and another set of measurements was performed after a new stable state was reached, including CI (thermodilution), PPV, SVV and IVCDV. Finally, in preload responsive patients, $500 \mathrm{~mL}$ of normal saline was infused over $10 \mathrm{~min}$. In these patients, a last set of measurements was recorded after the end of fluid infusion (CI (thermodilution), PPV, SVV and IVCDV).

Except Vt, ventilatory settings and treatments were unchanged during the study period. The intrabdominal pressure and the central venous pressure were measured at each study step. The CI measured by transpulmonary thermodilution and pulse contour analysis was continuously recorded by the PiCCO Win 4.0 software (Pulsion Medical Systems). The intravascular, intra-abdominal and airway pressure signals were continuously recorded by using a data acquisition software (HEM 4.2, Notocord, Croissy-sur-Seine, France).

\section{Statistical analysis}

Patients in whom PLR, performed at $\mathrm{Vt}=6 \mathrm{~mL} / \mathrm{kg}$, induced an increase in CI (measured by pulse contour analysis) $\geq 10 \%$, were defined as preload responders. Normality of data distribution was assessed visually. Variables were summarized as mean $\pm S D$ (if normally distributed), median and interquartile range (if non-normally distributed) or counts and percentages. Variables before and after fluid administration were compared by a paired Student $t$ test (if normally distributed) or a Wilcoxon test (if non-normally distributed). Variables between preload responders and non-responders were compared using a two-sample Student $\mathrm{t}$ test (if normally distributed), a Mann-Whitney U test (if non-normally distributed), a Chi-square test or a Fisher exact test, as indicated.

Receiver operating characteristic (ROC) curves (with 95\% confidence interval) were generated for quantifying the ability of the following variables to detect preload responsiveness: (1) IVCDV, PPV and SVV at baseline (Vt of $6 \mathrm{~mL} / \mathrm{Kg})$; (2) changes in IVCDV $\left(\triangle \mathrm{IVCDV}_{\mathrm{Vt}}\right)$, in PPV $\left(\triangle \mathrm{PPV}_{\mathrm{Vt}}\right)$ and in SVV $\left(\Delta \mathrm{SVV}_{\mathrm{Vt}}\right)$ induced by the Vt challenge, expressed either as the change in absolute value (value during Vt challenge - value at baseline) or as the percent relative change from the baseline value ((value during Vt challenge - value at baseline)/value at baseline $\times 100)$; (3) changes in IVCDV $\left(\triangle \mathrm{IVCDV}_{\mathrm{PLR}}\right)$, in PPV $\left(\triangle P P V_{\text {PLR }}\right)$ and in SVV $\left(\Delta \mathrm{SVV}_{\mathrm{PLR}}\right)$ induced by the PLR test, expressed either as the change in absolute value (value during PLR - value at baseline) or as the percent relative change from the baseline value ((value during PLR - value at baseline)/value at baseline $\times 100)$; the 
areas under ROC curves (AUROC) were compared by the Hanley-McNeil test. The best diagnostic threshold was determined as the one providing the best Youden index (sensitivity + specificity -1 ). The echocardiographic measurements were performed offline without knowing the results of the PLR test, but the values of PPV were collected at the same time as CI, knowing its changes during the PLR test.

The least significant change of IVCDV was obtained from six successive measurements of IVCDV performed during haemodynamic stability at $\mathrm{Vt}=6 \mathrm{~mL} / \mathrm{kg}$, by the same operator, removing the probe from the patient's skin for each measurement, as previously described [13].

In order to demonstrate a significant difference between groups of $\triangle \mathrm{IVCDV}_{\mathrm{Vt}}$, assuming a precision of the IVC measurement of $12 \%[16,17]$ with an $\alpha$ risk of $5 \%$ and a $\beta$ risk of $20 \%$, we planned to include 15 preload responders and 15 preload non-responders. Statistical analysis was performed with MedCalc 11.6.0 software (MedCalc, Mariakerke, Belgium).

\section{Results}

\section{Patients}

Forty-two patients were screened (Additional file 1: Supplementary Figure 3 ). Five were not included because of haemodynamic instability, and seven due to a poor ultrasound window. No patient was excluded for other reasons. Thirty patients were finally included and analysed.
All patients with a positive PLR test received volume expansion. Their characteristics are detailed in Table 1 . At the time of the study, propofol was administered in $28(93 \%)$ patients and remifentanil in 25 (83\%) patients. Neuromuscular blocking agents were used in six (20\%) patients. The intra-observer variability of the measurement of IVCDV at baseline was 9 [3-18]\%.

\section{Changes in $\mathrm{Cl}$ over study steps, characteristics of preload responders and non-responders}

The PLR test (performed at $\mathrm{Vt}=6 \mathrm{~mL} / \mathrm{kg}$ ) increased $\mathrm{CI} \geq 10 \%$ in 15 preload responders. Patient characteristics are detailed in Table 1. Increasing Vt from 6 to $8 \mathrm{~mL} /$ $\mathrm{kg}$ decreased CI and VTI in preload responders, but not in preload non-responders (Table 2). In preload responders, fluid infusion increased $\mathrm{CI} \geq 15 \%$ in all the patients.

\section{Changes in IVCDV over study steps, detection of preload responsiveness through IVC indices}

At baseline at $\mathrm{Vt}=6 \mathrm{~mL} / \mathrm{kg}$, the end-expiratory IVC diameter as well as IVCDV were similar between preload responders and preload non-responders (Table 2). $\triangle \mathrm{IVCDV}_{\text {PLR }}$ was larger in preload responders than in preload non-responders (Table 3, Additional file 1: Supplementary Figure 4). $\triangle \mathrm{IVCDV}_{\mathrm{PLR}}$ expressed in percent change from the baseline value reliably detected preload responsiveness, with a diagnostic threshold of $-24 \%$

Table 1 Patient characteristics at baseline

\begin{tabular}{|c|c|c|c|}
\hline & Preload responders $(n=15)$ & Preload non-responders $(n=15)$ & $p$ value \\
\hline Age (years) & $63 \pm 18$ & $70 \pm 10$ & 0.37 \\
\hline Male gender $(n, \%)$ & $12(80.0)$ & $11(73.3)$ & 0.32 \\
\hline SAPS2 & $52 \pm 15$ & $56 \pm 14$ & 0.29 \\
\hline Mortality $(n, \%)$ & $7(46.7)$ & $6(40.0)$ & 1.00 \\
\hline Septic shock $(n, \%)$ & $11(73.3)$ & $12(80.0)$ & 0.14 \\
\hline Cardiogenic shock ( $n, \%)$ & $2(13.3)$ & $2(13.3)$ & 0.55 \\
\hline Hypovolemic shock ( $n, \%)$ & $1(7.2)$ & $1(7.2)$ & 1.00 \\
\hline Vasoplegic shock (non-septic) ( $n, \%)$ & $1(7.2)$ & $0(0.0)$ & 0.12 \\
\hline $\operatorname{CRRT}(n, \%)$ & $3(20.0)$ & $4(26.7)$ & 0.18 \\
\hline $\operatorname{ARDS}(n, \%)$ & $6(40.0)$ & $5(33.3)$ & 0.47 \\
\hline Lactate (mmol/L) & $1.8 \pm 0.6$ & $1.3 \pm 0.6$ & 0.88 \\
\hline $\mathrm{PaO}_{2} / \mathrm{FiO}_{2}$ & $228 \pm 105$ & $276 \pm 105$ & 0.55 \\
\hline PEEP $\left(\mathrm{cmH}_{2} \mathrm{O}\right)$ & $10.7 \pm 3.6$ & $10.4 \pm 3.0$ & 0.63 \\
\hline $\mathrm{C}_{\mathrm{rs}}\left(\mathrm{mL} / \mathrm{cmH}_{2} \mathrm{O}\right)$ & $31 \pm 12$ & $32 \pm 13$ & 0.66 \\
\hline Acute cor pulmonale $(n, \%)$ & $0(0.0)$ & $0(0.0)$ & 1.00 \\
\hline LVEF (\%) & $45 \pm 9$ & $49 \pm 11$ & 0.67 \\
\hline Patients receiving norepinephrine $(n, \%)$ & $15(100.0)$ & $15(100.0)$ & 1.00 \\
\hline Dose of norepinephrine ( $\mu \mathrm{g} / \mathrm{kg} / \mathrm{min})$ & $1.2 \pm 0.6$ & $0.6 \pm 0.4$ & 0.02 \\
\hline
\end{tabular}

$P$ values in bold: $<0.05$

$A R D S$ acute respiratory distress syndrome, $C R R T$ continuous renal replacement therapy, $C_{r s}$ compliance of the respiratory system, $L V E F$ left ventricular ejection fraction, $\mathrm{PaO}_{2} / \mathrm{FiO}_{2}$ ratio of the arterial oxygen partial pressure over the oxygen inspired fraction, PEEP positive end-expiratory pressure, SAPS simplified acute physiologic score 


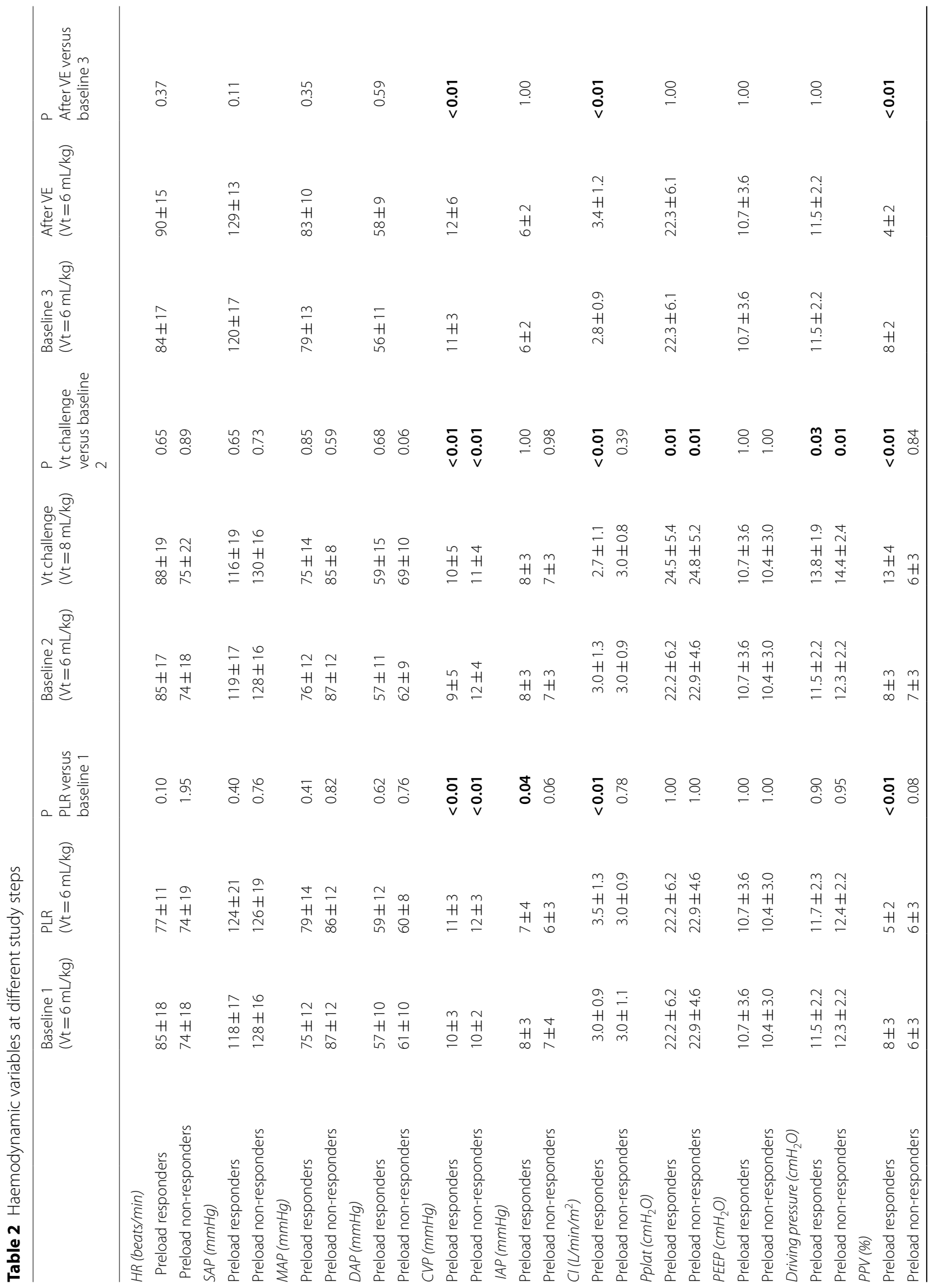




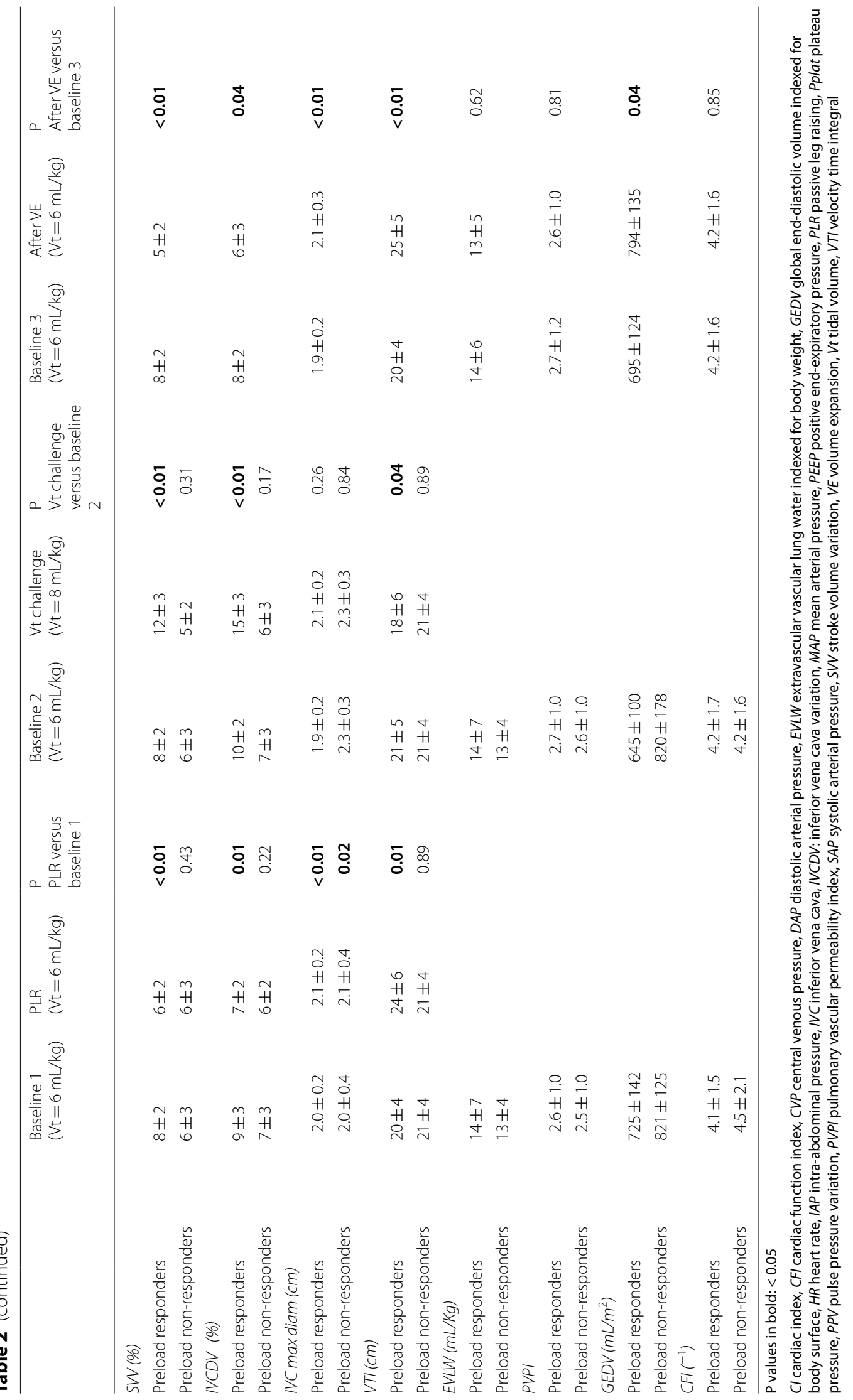


Table 3 Indices of preload responsiveness at different study times in preload responders and non-responders

\begin{tabular}{|c|c|c|c|}
\hline & $\begin{array}{l}\text { Effects of PLR } \\
(\mathrm{Vt}=6 \mathrm{~mL} / \mathrm{kg})\end{array}$ & $\begin{array}{l}\text { Effects of the Vt challenge } \\
(\mathrm{Vt}=8 \mathrm{~mL} / \mathrm{kg})\end{array}$ & $\begin{array}{l}\text { Effects of VE } \\
(\mathrm{Vt}=6 \mathrm{~mL} / \mathrm{kg})\end{array}$ \\
\hline \multicolumn{4}{|l|}{$\Delta \mathrm{Cl}$ (\% change) } \\
\hline $\begin{array}{l}\text { Preload responders } \\
\text { Preload non-responders }\end{array}$ & $\begin{array}{l}18 \pm 6 \\
4 \pm 4\end{array}$ & $\begin{array}{l}-9 \pm 8 \\
2 \pm 6\end{array}$ & \multirow[t]{2}{*}{$25 \pm 9$} \\
\hline \multicolumn{3}{|l|}{$\Delta V T I$ (\% change) } & \\
\hline $\begin{array}{l}\text { Preload responders } \\
\text { Preload non-responders }\end{array}$ & $\begin{array}{l}16 \pm 3 \\
1 \pm 1\end{array}$ & $\begin{array}{l}-10 \pm 7 \\
1 \pm 7\end{array}$ & \multirow[t]{2}{*}{$+16 \pm 8$} \\
\hline \multicolumn{3}{|l|}{$\triangle P P V(\%$ change) } & \\
\hline $\begin{array}{l}\text { Preload responders } \\
\text { Preload non-responders }\end{array}$ & $\begin{array}{l}-38 \pm 16 \\
-4 \pm 8\end{array}$ & $\begin{array}{l}64 \pm 42 \\
1 \pm 28\end{array}$ & $-50 \pm 12$ \\
\hline \multicolumn{4}{|l|}{$\triangle P P V$ (absolute change) } \\
\hline $\begin{array}{l}\text { Preload responders } \\
\text { Preload non-responders }\end{array}$ & $\begin{array}{l}-3 \pm 1 \\
0 \pm 1\end{array}$ & $\begin{array}{l}5 \pm 2 \\
0 \pm 1\end{array}$ & $-4 \pm 2$ \\
\hline $\begin{array}{l}\text { P preload non-responders versus preload responders } \\
\triangle S V V \text { (\% change) }\end{array}$ & $<0.01$ & $<0.01$ & \\
\hline $\begin{array}{l}\text { Preload responders } \\
\text { Preload non-responders }\end{array}$ & $\begin{array}{l}-24 \pm 20 \\
1 \pm 15\end{array}$ & $\begin{array}{l}44 \pm 22 \\
-1 \pm 3\end{array}$ & $-40 \pm 17$ \\
\hline $\begin{array}{l}\text { P preload non-responders versus preload responders } \\
\triangle S V V \text { (absolute change) }\end{array}$ & $<0.01$ & $<0.01$ & \\
\hline $\begin{array}{l}\text { Preload responders } \\
\text { Preload non-responders }\end{array}$ & $\begin{array}{l}-2 \pm 2 \\
0 \pm 1\end{array}$ & $\begin{array}{l}3 \pm 2 \\
-1 \pm 3\end{array}$ & $-4 \pm 2$ \\
\hline \multicolumn{4}{|l|}{$\triangle I V C D V(\%$ change) } \\
\hline $\begin{array}{l}\text { Preload responders } \\
\text { Preload non-responders }\end{array}$ & $\begin{array}{l}-26 \pm 28 \\
-3 \pm 20\end{array}$ & $\begin{array}{l}91 \pm 72 \\
-10 \pm 52\end{array}$ & $-25 \pm 15$ \\
\hline \multicolumn{4}{|l|}{$\triangle I V C D V$ (absolute change) } \\
\hline $\begin{array}{l}\text { Preload responders } \\
\text { Preload non-responders }\end{array}$ & $\begin{array}{l}-2 \pm 3 \\
-1 \pm 2\end{array}$ & $\begin{array}{l}6 \pm 4 \\
-1 \pm 4\end{array}$ & \multirow[t]{2}{*}{$-2 \pm 4$} \\
\hline P preload non-responders versus preload responders & 0.51 & $<0.01$ & \\
\hline
\end{tabular}

$P$ values in bold: $<0.05$

$\triangle C l$ percent changes in cardiac index, $\triangle I V C D V$ percent changes in the inferior vena cava diameter variation, $\triangle P P V$ percent changes in pulse pressure variation, $\triangle S V V$ percent changes in stroke volume variation, $\triangle V T I$ percent changes in velocity time integral

(Table 4). $\triangle \mathrm{IVCDV}_{\text {PLR }}$ was significantly correlated with the PLR-induced changes in CI. $\triangle \mathrm{IVCDV}_{\text {PLR }}$ expressed in absolute change did not detect preload responsiveness (AUROC not different from 0.5) and was not correlated with the PLR-induced changes in CI (Table 4, Fig. 1).

$\triangle \mathrm{IVCDV}_{\mathrm{Vt}}$ was larger in preload responders than in preload non-responders (Table 3, Additional file 1: Supplementary Figure 4). $\triangle \mathrm{IVCDV}_{\mathrm{Vt}}$ expressed in percent change from the baseline value reliably detected preload responsiveness, with a diagnostic threshold of $4 \%$ (Table 4). This was also the case for $\triangle \mathrm{IVCDV}_{\mathrm{Vt}}$ expressed in absolute change (Table 4, Fig. 1). Both indices were correlated with the PLR-induced changes in CI (Table 4).

\section{Changes in PPV and SVV over study steps, detection} of preload responsiveness through PPV/SVV indices $\triangle \mathrm{PPV}_{\mathrm{PLR}}$ was larger in preload responders than in preload non-responders (Table 3, Additional file 1: Supplementary Figure 4). The PLR-induced changes in PPV reliably detected preload responsiveness, either expressed in percent change from baseline (Table 4) or in absolute change (Table 4, Fig. 1). Both indices were correlated with the PLR-induced changes in CI (Table 4). Similar results were observed for $\Delta \operatorname{SVV}_{\text {PLR }}$ (Table 4).

$\triangle \mathrm{PPV}_{\mathrm{Vt}}$ was larger in preload responders than in preload non-responders (Table 3, Additional file 1: Supplementary Figure 4). The Vt challenge-induced changes in PPV reliably detected preload responsiveness, either 


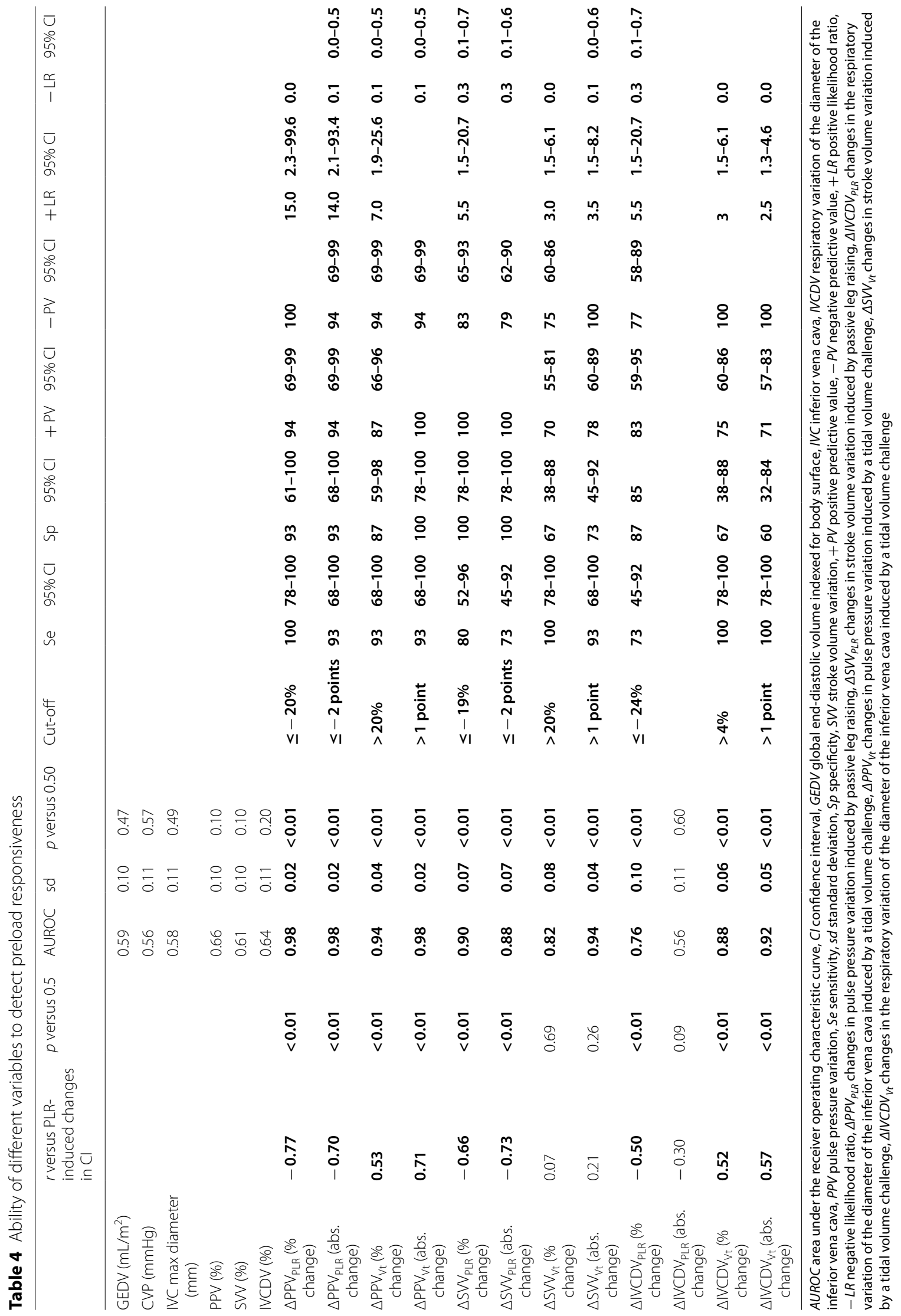




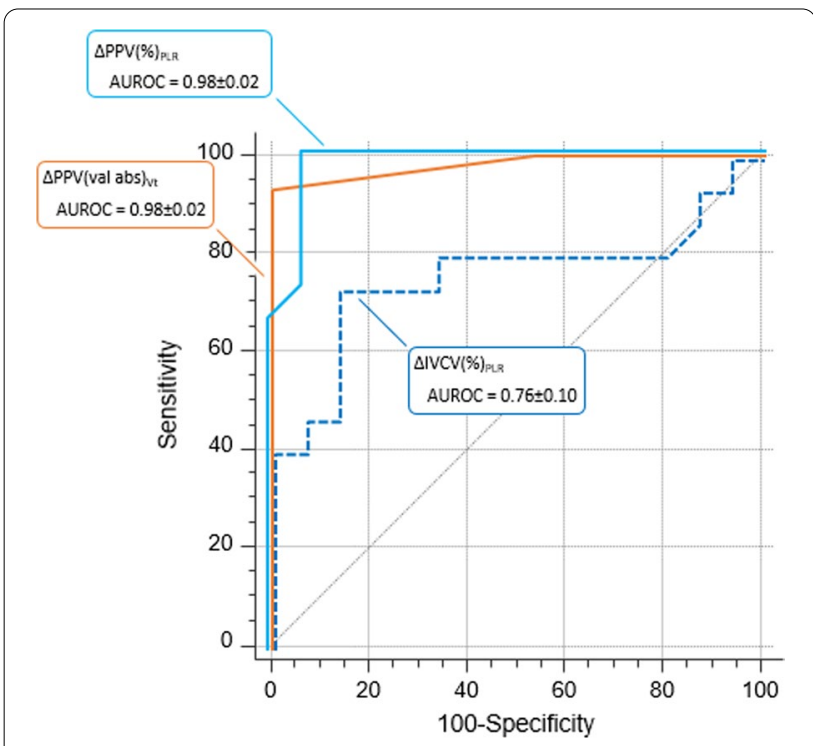

Fig. 1 Receiver operating characteristic curves describing the ability to diagnose preload responsiveness of the changes in passive leg raising-induced changes of pulse pressure variation in percent $\left(\triangle P P V(\%)_{P L R}\right)$, passive leg raising-induced changes and of inferior vena cava variation in percent $\left(\triangle \mathrm{IVCDV}(\%)_{\mathrm{PLR}}\right)$, and of the tidal volume challenge-induced changes of pulse pressure variation in absolute value $\left(\triangle P P V\left(v^{2} \text { labs }\right)_{V t}\right)$. AUROC: area under the receiver operating characteristic curve (expressed as mean \pm SD)

expressed in percent change from baseline (Table 4) or in absolute change (Table 4, Fig. 1). Both indices were correlated with the PLR-induced changes in CI (Table 4).

$\Delta \mathrm{SVV}_{\mathrm{Vt}}$ was larger in preload responders than in preload non-responders (Table 3, Additional file 1: Supplementary Figure 4). The Vt challenge-induced changes in SVV reliably detected preload responsiveness, either expressed in percent change from baseline (Table 4) or in absolute change (Table 4, Fig. 1). However, both indices were not correlated with the PLR-induced changes in CI (Table 4).

\section{Comparisons of ROC curves}

The AUROC for $\triangle I_{V C D V} V_{\text {PLR }}$ expressed in absolute value was significantly lower than the AUROC of any other index $\left(\triangle \mathrm{IVCDV}_{\mathrm{Vt}}, \Delta \mathrm{PPV}_{\mathrm{Vt}}, \Delta \mathrm{SVV}_{\mathrm{Vt}}, \Delta \mathrm{PPV}_{\mathrm{PLR}}\right.$ and $\triangle S V V_{\text {PLR }}$ expressed in percent change or in absolute value and $\triangle \mathrm{IVCDV}_{\mathrm{PLR}}$ expressed in percent change). There was no significant difference of AUROC between all other indices.

\section{Discussion}

In this study performed in critically ill patients, we show that the PLR-induced decrease in IVCDV has a reliable diagnostic value but only expressed in percent change and that the increase in IVCDV during a Vt challenge may detect preload responsiveness, but with a diagnostic threshold far lower than the least significant change of IVCDV. Along with a previous study [18], we also suggest the PLR-induced decrease in PPV detects preload responsiveness, we suggest that the variations in IVC diameter with mechanical ventilation are poor markers of preload responsiveness in case of $\mathrm{Vt}=6 \mathrm{~mL} / \mathrm{kg}$, and we show that the increase in PPV during a Vt challenge detects preload responsiveness.

Several tests are today available for detecting preload responsiveness and predicting the response of cardiac output to fluid infusion [3]. Nevertheless, they differ regarding their conditions of use and the monitoring devices that are required to assess their effects. PPV and SVV are reliable, but their reliability is severely decreased in case of spontaneous breathing, cardiac arrythmias, low lung compliance and $\mathrm{Vt}<8 \mathrm{~mL} / \mathrm{kg}$ [1]. The PLR test has a similar reliability $[19,20]$, but its main drawback is that its effects cannot be assessed simply on systolic or pulse arterial pressure [8]. The present study describes how PPV and SVV could be used to assess preload responsiveness in case of low $\mathrm{Vt}<8 \mathrm{~mL} / \mathrm{kg}$, and how the effects of the PLR test can be assessed without measuring cardiac output directly.

First, our findings suggest the IVCDV was not a reliable indicator of preload responsiveness in case of $\mathrm{Vt}=6 \mathrm{~mL} /$ $\mathrm{kg}$, as it has been already shown by a previous study [6] (Additional file 1: Supplementary Table 1). The changes in IVC dimensions under mechanical ventilation are due to the cyclic changes in its transmural pressure created by the changes in central venous pressure and likely in intra-abdominal pressure. Then it is not surprising that a low Vt, inducing lower changes in intrathoracic and transmural pressures, is responsible for a lower diagnostic ability compared to $\mathrm{Vt} \geq 8 \mathrm{~mL} / \mathrm{kg}$. Nevertheless, it is important to emphasize that the reliability of IVCDV for detecting preload responsiveness has been found to be poor or moderate by many studies and meta-analyses, even in studies including patients with $\mathrm{Vt} \geq 8 \mathrm{~mL} / \mathrm{kg}$ [21, 22]. Along with these studies, the present one shows that IVCDV is likely the dynamic index of fluid responsiveness with the poorest diagnostic value.

Second, we found that the PLR-induced decrease in PPV reliably detected preload responsiveness, whatever the way it was calculated. This was the case when expressed either in absolute or in relative change, and 
$\triangle P P V_{\mathrm{PLR}}$ was the index with the highest correlation with the degree of preload responsiveness, as assessed by the PLR-induced changes in CI. $\triangle S V_{\text {PLR }}$ provided similar results, though the correlation with preload responsiveness intensity was a bit lower. This result might be of clinical importance. Indeed, PLR, the main alternative to PPV and SVV in case of $\mathrm{Vt}<8 \mathrm{~mL} / \mathrm{kg}$, requires a direct measurement of cardiac output [8] and many studies attempted to find cardiac output surrogates that may be used for this purpose. Provided that the patient is equipped with an arterial catheter, PPV is readily available and assessing the effects of PLR on it might be very easy. In this regard, this result should be compared to the assessment of the PLR test through the perfusion index of plethysmography [23] or its respiratory variation [24].

Third, the PLR-induced decrease in IVCDV detected preload responsiveness but only when expressed in percent change. Even in this way, the predictive ability was not excellent: the AUROC was $0.76 \pm 0.10$, tending to be lower than for the PLR-induced changes in PPV. The correlation with the PLR-induced changes in CI was only -0.50 . When IVCDV changes were expressed in absolute value, it changes during PLR were no more able to detect preload responsiveness. This is not surprising, as IVCDV is itself a poorer index of preload responsiveness than PPV. Then, its relative changes during preload manipulations must be poorer than the changes in PPV. Also, moving the patient to the PLR position undoubtedly introduces a difficulty in the measurement of IVCDV, which can only contribute to hamper its diagnostic value.

Fourth, we suggest that the Vt challenge is a reliable means to test preload responsiveness in case of low $\mathrm{Vt}$, as it has been already shown $[10,25]$. The diagnostic threshold expressed in absolute value (1\%) was lower than already observed (3.5\%) [10], and like the one reported by Messina et al. [25]. This point is very important, because a 1-point change is very low regarding the mean of PPV value. This may induce diagnostic mistakes, especially in patients in whom PPV is unstable. The effects of the Vt challenge on SVV were worse, which is not surprising as SVV results from an estimation of stroke volume from arterial pulse pressure [15]. The AUROC tended to be smaller than that for $\triangle P P V_{V t}$, and the correlation between the PLR-induced changes in CI and $\Delta \mathrm{SVV}_{\mathrm{Vt}}$ was not significant.

In theory, preload responsiveness observed at $\mathrm{Vt}=8 \mathrm{~mL} / \mathrm{kg}$ should not imply that it also exists at $\mathrm{Vt}=6 \mathrm{~mL} / \mathrm{kg}$, as increasing $\mathrm{Vt}$ has changed the degree of preload responsiveness. In theory, there might be some false positives to the Vt challenge when assessing preload responsiveness. Nevertheless, our results suggest that this is not a significant limitation, likely because the change in cardiac preload is not of enough amplitude for transforming a preload responsive patient at $\mathrm{Vt}=8 \mathrm{~mL} /$ $\mathrm{kg}$ in a preload non-responsive patient at $\mathrm{Vt}=6 \mathrm{~mL} / \mathrm{kg}$. We observed no false positives when using $\Delta \mathrm{PPV}_{\mathrm{Vt}}$ to assess preload responsiveness.

Of note, the Vt challenge induced very large increases in PPV, SVV and IVCDV, despite the respiratory driving pressure only slightly increased. The Vt challenge induced changes in PPV, SVV and IVCDV were much larger than these induced by PLR, although PLR increases cardiac preload to a larger extent. This might be explained by the fact that PLR increases cardiac preload, moving the equilibrium point rightward on the cardiac function curve, where it is flatter. By contrast, because it decreases cardiac preload, the Vt challenge moves the equilibrium point leftward, where the curve is steeper. This makes changes the respiratory changes in stroke volume (and PPV) larger (see Additional file 1: Figure 1).

Fifth, the results regarding the changes in IVCDV during a Vt challenge were disappointing. The AUROC was significantly different from 0.5 , for absolute as for relative changes, but the diagnostic threshold was much lower than the least significant change of IVCDV we calculated. Also, the correlation between $\triangle \mathrm{IVCDV}_{\mathrm{Vt}}$ and the PLRinduced changes in CI was weak. This is a disappointing result, because it means that the Vt challenge can be performed only if an arterial line is present.

The first limitation of the study is that we assessed preload responsiveness through the effects of a PLR test and not through a fluid challenge. This is explained by ethical reasons, as it would be today unacceptable to plan fluid infusion in preload unresponsive patients only for research purposes. Nevertheless, one must admit that the reliability of the PLR test has been well established by a number of previous studies [19,20]. Second, we did not investigate the superior vena cava collapsibility, which is an equivalent of IVCDV [26]. Third, the dose of norepinephrine was higher in preload responders than in preload non-responders. This may have impaired the comparability between groups in terms of IVC variability, because norepinephrine decreases the IVC compliance, and in terms of PLR-induced increases in cardiac preload, because norepinephrine may decrease the volume of venous blood mobilized during the PLR test. Fourth, we did not assess the "grey zone" of the tests we investigated, which may avoid binary decisions when using such tests [27]. Finally, we did not include in our analysis some other interesting tests predicting fluid responsiveness, such as for instance the recruitment manoeuvres. 


\section{Conclusion}

The present study suggests that IVCDV is not a reliable indicator of preload responsiveness in patients with $\mathrm{Vt}$ at $6 \mathrm{~mL} / \mathrm{kg}$. It describes how the changes in IVCDV, like the changes in PPV, induced by a PLR test and by a transient increase in $\mathrm{Vt}$ from 6 to $8 \mathrm{~mL} / \mathrm{kg}$ detect preload responsiveness assessed at $6 \mathrm{~mL} / \mathrm{kg}$.

\section{Supplementary Information}

The online version contains supplementary material available at https://doi. org/10.1186/s13054-021-03515-7.

Additional file 1. Supplemental Figure 1: Principle of the hypothesis; Supplemental Figure 2: Study Protocol; Supplemental Figure 3: Flow Chart; Supplementary figure 4; Supplemental Table 1: Characteristics of Studies.

\section{Acknowledgements}

Not applicable.

\section{Authors' contributions}

TT collected data, analysed and interpreted the data and drafted the manuscript. FG collected data, analysed and contributed to interpret the data and to draft the manuscript. JLT designed the study, contributed to interpreting the data and drafting the manuscript. RS contributed to data analysis. XM designed the study, supervised it, interpreted the data and drafted the manuscript. All authors approved the final version of the manuscript.

\section{Funding}

No funding.

\section{Availability of data and materials}

Individual, de-identified participant data are available from the corresponding author on reasonable request.

\section{Declarations}

\section{Ethics approval and consent to participate}

Information and consent obtained for each patient. Name of the ethics committee that approved the study and the committee's reference number: Comité pour la Protection des Personnes, Ile-de-France VII. Trial registration ID RCB: 2016-A00893-48. Registered 26 July 2016. The patients were included prospectively.

\section{Consent for publication}

All authors of the manuscript have read and agreed to its content and are accountable for all aspects of the accuracy and integrity of the manuscript. The data were used anonymously.

\section{Competing interests}

$J$-L Teboul and X Monnet are members of the Medical Advisory Board of Pulsion Medical Systems. J-L Teboul and X Monnet have given lectures for Cheetah Medical. The other authors have no conflict of interest to declare. No financial support.

Received: 23 November 2020 Accepted: 18 February 2021 Published online: 18 March 2021

\section{References}

1. Teboul JL, Monnet X, Chemla D, et al. Arterial pulse pressure variation with mechanical ventilation. Am J Respir Crit Care Med. 2019;199(1):22-31.
2. De Backer D, Heenen S, Piagnerelli M, et al. Pulse pressure variations to predict fluid responsiveness: influence of tidal volume. Intensive Care Med. 2005:31(4):517-23.

3. Monnet $X$, Marik PE, Teboul JL. Prediction of fluid responsiveness: an update. Ann Intensive Care. 2016;6(1):111.

4. Piskin $\mathrm{O}, \mathrm{Oz}$ II. Accuracy of pleth variability index compared with inferior vena cava diameter to predict fluid responsiveness in mechanically ventilated patients. Medicine (Baltimore). 2017;96(47):e8889.

5. Monnet X, Bleibtreu A, Ferré A, et al. Passive leg-raising and endexpiratory occlusion tests perform better than pulse pressure variation in patients with low respiratory system compliance. Crit Care Med. 2012:40(1):152-7.

6. Baker AK, Partridge RJ, Litton E, et al. Assessment of the plethysmographic variability index as a predictor of fluid responsiveness in critically ill patients: a pilot study. Anaesth Intensive Care. 2013;41(6):736-41.

7. Liu Y, Wei LQ, Li GQ, et al. Pulse pressure variation adjusted by respiratory changes in pleural pressure, rather than by tidal volume, reliably predicts fluid responsiveness in patients with acute respiratory distress syndrome. Crit Care Med. 2016;44(2):342-51.

8. Monnet $X$, Teboul JL. Passive leg raising: five rules, not a drop of fluid! Crit Care. 2015;19(1):18

9. Myatra SN, Monnet X, Teboul JL. Use of 'tidal volume challenge'to improve the reliability of pulse pressure variation. Crit Care. 2017;21(1):60.

10. Myatra SN, Prabu NR, Divatia JV, et al. The changes in pulse pressure variation or stroke volume variation after a "tidal volume challenge" reliably predict fluid responsiveness during low tidal volume ventilation. Crit Care Med. 2017:45(3):415-21.

11. Monnet $X$, Dres M, Ferré A, et al. Prediction of fluid responsiveness by a continuous non-invasive assessment of arterial pressure in critically ill patients: comparison with four other dynamic indices. Br J Anaesth. 2012;109(3):330-8.

12. Beurton A, Teboul JL, Girotto V, et al. Intra-abdominal hypertension is responsible for false negatives to the passive leg raising test. Crit Care Med. 2019;47(8):e639-47.

13. Jozwiak M, Mercado P, Teboul $\mathrm{J} L$, et al. What is the lowest change in cardiac output that transthoracic echocardiography can detect? Crit Care 2019;23(1):116.

14. Monnet $X$, Persichini $R$, Ktari $M$, et al. Precision of the transpulmonary thermodilution measurements. Crit Care. 2011;15(4):R204.

15. Jozwiak M, Monnet X, Teboul JL. Pressure waveform analysis. Anesth Analg. 2018;126(6):1930-3.

16. Barbier C, Loubieres Y, Schmit C, Hayon J, Ricome JL, Jardin F, et al. Respiratory changes in inferior vena cava diameter are helpful in predicting fluid responsiveness in ventilated septic patients. Intensive Care Med. 2004;30(9):1740-6.

17. Feissel M, Michard F, Faller JP, Teboul JL. The respiratory variation in inferior vena cava diameter as a guide to fluid therapy. Intensive Care Med. 2004;30(9):1834-7.

18. Monnet $X$, Marik $P$, Teboul JL. Passive leg raising for predicting fluid responsiveness: a systematic review and meta-analysis. Intensive Care Med. 2016:42(12):1935-47.

19. Geerts B, De Wilde R, Aarts L, et al. Pulse contour analysis to assess hemodynamic response to passive leg raising. J Cardiothorac Vasc Anesth. 2011;25:48-52.

20. Cherpanath TG, Hirsch A, Geerts BF, et al. Predicting fluid responsiveness by passive leg raising: a systematic review and meta-analysis of 23 clinical trials. Crit Care Med. 2016;44(5):981-91.

21. Das SK, Choupoo NS, Pradhan D, Saikia P, Monnet X. Diagnostic accuracy of inferior vena caval respiratory variation in detecting fluid unresponsiveness: A systematic review and meta-analysis. Eur J Anaesthesiol. 2018;35(11):831-9.

22. Long E, Oakley E, Duke T, Babl FE. Paediatric research in emergency departments international C. Does respiratory variation in inferior vena cava diameter predict fluid responsiveness: a systematic review and meta-analysis. Shock. 2017:47(5):550-9.

23. Beurton A, Teboul JL, Gavelli F, et al. The effects of passive leg raising may be detected by the plethysmographic oxygen saturation signal in critically ill patients. Crit Care. 2019;23(1):19.

24. Delerme S, Castro S, Freund Y, et al. Relation between pulse oximetry plethysmographic waveform amplitude induced by passive leg raising 
and cardiac index in spontaneously breathing subjects. Am J Emerg Med. 2010;28(4):505-10.

25. Messina A, Montagnini C, Cammarota G, et al. Tidal volume challenge to predict fluid responsiveness in the operating room: an observational study. Eur J Anaesthesiol. 2019;36(8):583-91.

26. Vieillard-Baron A, Chergui K, Rabiller A, et al. Superior vena caval collapsibility as a gauge of volume status in ventilated septic patients. Intensive Care Med. 2004;30(9):1734-9.
27. Cannesson M, Le Manach Y, Hofer CK, et al. Assessing the diagnostic accuracy of pulse pressure variations for the prediction of fluid responsiveness: a "gray zone" approach. Anesthesiology. 2011;115(2):231-41.

\section{Publisher's Note}

Springer Nature remains neutral with regard to jurisdictional claims in published maps and institutional affiliations.
Ready to submit your research? Choose BMC and benefit from:

- fast, convenient online submission

- thorough peer review by experienced researchers in your field

- rapid publication on acceptance

- support for research data, including large and complex data types

- gold Open Access which fosters wider collaboration and increased citations

- maximum visibility for your research: over $100 \mathrm{M}$ website views per year

At BMC, research is always in progress.

Learn more biomedcentral.com/submissions 